\title{
Pathogenicity for Mice of a Recombinant of Vaccinia Virus and Protection Against Infection with a Lethal Virus
}

\author{
Irina Gurt and Ehud Katz*
}

Chanock Center of Virology, Institute for Medical Research Israel-Canada, Hebrew University-Hadassah Medical School, P.O.Box 12272, Jerusalem 91120, Israel

\begin{abstract}
The population of the stock of the Lister strain of vaccinia virus, applied in Israel for immunization against smallpox, was found to be heterogeneous. A middle-size plaque (MP) virus was found to be the most attenuated for mice, out of the three variants which we characterized. Previously we found that C-terminal truncation of the A33R viral envelope protein of vaccinia virus leads to an enhanced release of free virus from the infected cells and to attenuation of the virus for mice. A recombinant of the MP variant with such truncation, was now constructed and found to release more progeny virus from the infected cells and slightly more attenuated for mice than its parent virus. This new recombinant of vaccinia virus may be useful when vaccination against smallpox would be required again, in the future.
\end{abstract}

Keywords: Lister strain, pathogenicity, protection, vaccinia virus.

\section{INTRODUCTION}

Smallpox [1] was declared by the World Health Organization in 1979, as an eradicated disease and the routine vaccination against variola virus stopped a year later $[2,3]$, however, the risk of using this highly pathogenic virus as a biological warfare agent, still exists $[4,5]$. Since a large proportion of the human population has no immunity against variola virus anymore, the morbidity rate is expected to be significantly high, in case such terrorist action will take place. The Lister (Elstree) strain was one of vaccinia virus strains used for immunization against infection by variola virus and was the most widely used between 1968 and 1971, in spite of causing, although quite rarely, serious adverse reactions like encephalitis, and more frequently, local reactions [6-8]. In order to lower the risk of complications, more attenuated viruses, such as modified vaccinia virus Ankara (MVA) were later developed [9-12], although their ability to protect the human host against this deadly disease under epidemic conditions, was not experienced yet.

Another approach to obtain a more suitable virus for immunization against smallpox, was undertaken by us. We characterized the virus population comprising the Lister stock, used in Israel for many years for vaccination against smallpox. This stock was found to be heterogeneous and contained a mixture of viruses, forming plaques of different diameter in tissue cultures [13]. Three variants of the Lister stock were isolated and plaque purified: large plaque (LP), middle plaque (MP) and small plaque (SP); their different diameter in the plaque assay is clearly visible [13]. Furthermore, initial studies which we performed showed that

*Address correspondence to this author at the Chanock Center of Virology, Institute for Medical Research Israel-Canada, Hebrew University-Hadassah Medical School. P.O. Box 12272, Jerusalem 91120 Israel;

Tel: 972-2-6758557; Fax: 972-2-6758558;

E-mail: katzeh@cc.huji.ac.il the virulence of the different virus isolates for mice, varies significantly [13].

Previously we found that C-terminal truncation of 35 amino acids in the A33R envelope protein of vaccinia virus causes enhanced release of extracellular virions from infected cells at the completion of the growth cycle of the virus, and also to significant attenuation of the virus for mice [14].

The aims of the present study were: a) to further evaluate the pathogenicity of the different virus variants that comprised the stock of the Lister strain, following intranasal and intracranial infections of mice, b) to determine the protection the different variants induce in mice against a challenge with a lethal pox virus, and c) to construct and characterize a recombinant of the most attenuated variant selected, having the A33R truncation and which releases higher proportion of extracellular virus. Such virus may be more suitable for future vaccination against smallpox, if and when needed again.

\section{MATERIALS AND METHODOLOGY}

\section{Cells and Viruses}

BS-C-1 were grown in Dulbecco modified Eagle's medium (DMEM, Biological Industries, Beit Haemek, Israel), supplemented with 7\% newborn calf serum (NBCS, Biological Industries). The Lister strain of vaccinia virus, used in Israel for vaccination against smallpox, was obtained from the Central Virology Laboratories, Ministry of Health, Israel. The isolation of the three variants of this virus: LP, MP and SP and their initial characterization, were previously described by us [13].

Crude stocks of the Lister strain and its three variants were prepared in BS-C-1 cells, in DMEM supplemented with $2 \%$ NBCS. When an extensive cytopathic effect was visible, usually within 2-4 days, the cells were harvested, 
centrifuged and suspended in DMEM supplemented with 2\% $\mathrm{NBCS}$, and kept frozen at $-80^{\circ} \mathrm{C}$ until use. Purified virus was prepared from the cytoplasmic fraction of infected cells, obtained after Dounce homogenization and removal of the nuclei by low-speed centrifugation. The cytoplasmic fraction was layered on $36 \%$ sucrose in $10 \mathrm{mM}$ Tris $\mathrm{pH} 9.0$ and centrifuged in TST 28 rotor at $24,000 \mathrm{rpm}$ for $45 \mathrm{~min}$ at $4^{\circ} \mathrm{C}$. The virus pellet was suspended in Tris buffer and stored at $80^{\circ} \mathrm{C}$, until use.

\section{Plaque Assay}

Following adsorption of dilutions of virus samples to monolayers of BS-C-1 cells in 35 diameter plastic dishes (Nunc, Roskilde, Denmark) for $1 \mathrm{~h}$ at $37^{\circ} \mathrm{C}$, MEM-Eagle medium, containing 5\% NBCS and $0.5 \%$ methyl cellulose (Sigma, St. Louis, MO) was added. After incubation for 4 days at $37^{\circ} \mathrm{C}$, the semi-solid medium was removed, the cells were stained with $0.1 \%$ crystal violet in $20 \%$ ethanol and virus plaques were counted.

\section{One-Step Growth}

BS-C-1 cells were infected at a multiplicity of 3 PFU per cell for $1 \mathrm{~h}$ and then washed twice with fresh medium to remove unadsorbed virus. DMEM supplemented with $2 \%$ NBCS was then added. At various times thereafter, the cells and medium were harvested together, with the help of a rubber-policeman, and kept frozen at $80^{\circ} \mathrm{C}$. When determining separately the virus in the medium and that in the cells, the culture medium was first collected and clarified by low-speed centrifugation, to sediment detached cells and debris. The adherent cells were then scraped into $1 \mathrm{~mL}$ of fresh medium and combined with the pellet obtained following the previous centrifugation. The medium and the cells were kept frozen separately at $-80^{\circ} \mathrm{C}$. Just prior to titration, the preparations were thawed and frozen three times and sonicated for $30 \mathrm{~s}$, in order to break cells and disrupt virus aggregates. The virus titer was determined by plaque assay.

\section{Virulence for Mice}

All mice experiments were performed according to the strict regulations of the ethics committee of the Hebrew University-Hadassah Medical School (approval number: MD-0811052-4). Groups $(n=4)$ of 4-5 week-old female $\mathrm{Balb} / \mathrm{C}$ mice were anesthetized by inhalation of isoflurane (Rhodia Organique Fine Ltd, Avonmouth, Bristol, UK) and various doses of purified virus in a total volume of $20 \mu \mathrm{L}$ were dropped into the mice intranasally, using an Eppendorf pipette, or the virus, in a volume of $30 \mu \mathrm{L}$, was injected intracranially. The mice were weighed daily and those that had lost more than $25 \%$ of their initial body weight were euthanized.

\section{Virus in the Internal Organs of the Mouse}

The internal organs were removed from euthanized mice. They were weighed in a small plastic tube and $0.9 \mathrm{~mL}$ of DMEM containing 5\% NBCS was added. The tube was then frozen and thawed three times and its content was transferred to $1 \mathrm{~mL}$ glass homogenizer. Following homogenization, the material was sonicated for $30 \mathrm{~s}$ and centrifuged at $1000 \mathrm{rpm}$ for $7 \mathrm{~s}$ in an Eppendorf 5415 centrifuge. The supernatant was collected and virus titer was determined by plaque assay.

\section{Extraction of DNA from Infected Cells}

Infected cells, showing complete cytopathic effect, were removed from the bottom of the culture dish with a rubber policeman and then centrifuged. The cell pellet was resuspended in phosphate buffered saline and the DNA was extracted using QIA DNA Blood Mini Kit (Qiagen, Hilden, Germany), according to the instructions of the manufacturer.

\section{Enrichment of DNA by PCR}

For the enrichment of the DNA of A33R gene, primers of 5'-to-3' sequences GCGCAAGCACTAGGCATCAGTTC and GGTCGTTAGTAGGGAGGAGAACAAAG were used with the enzyme GoTag DNA polymerase (Promega, MI) for $45 \mathrm{~s}$. The PCR products were then purified using QIAquick PCR Purification Kit (Qiagen, Valencia, CA).

\section{Transfection}

To BS-C-1 cells at $70-80 \%$ confluency, Opti-MEM (Gibco, Invitrogen) was added. An hour later, the cells were infected with the virus at a multiplicity of 1 PFU per 20 cells. Two tubes were prepared: the first with $5 \mu \mathrm{g}$ of PCR products in $0.2 \mathrm{~mL}$ Opti-MEM and another with $10 \mu \mathrm{l}$ of Lipofectamine (Gibco) in $0.25 \mathrm{~mL}$ Opti-MEM. The two solutions were then mixed together and incubated for $25 \mathrm{~min}$ at room temperature. At $2 \mathrm{~h}$ after infection, the cells were washed twice and the DNA/Lipofectamine mixture was added. Four hours later, DMEM supplemented with $2 \%$ NBCS was added to the cells. After incubation for two days at $37^{\circ} \mathrm{C}$, the cultures were harvested, the cells and culture medium were separated by low speed centrifugation, and stored at $-80^{\circ} \mathrm{C}$, until infecting $\mathrm{BS}-\mathrm{C}-1$ cultures for the isolation of the recombinants.

\section{RESULTS AND DISCUSSION}

\section{Characterization of the three Variants of the Lister Strain of Vaccinia Virus}

First, we wished to select the most suitable virus of the Lister vaccine strain to be used for constructing the recombinant, having the $\mathrm{C}$-terminal truncated A33R protein. Previously, we isolated three variants of the Lister strain of vaccinia virus from the vaccine virus stock, which was used in Israel for many years for immunization against smallpox. These variants: Large plaque (LP), middle plaque (MP) and small plaque (SP) differ in the diameter of the plaques they form in BS-C-1 cultures under semi-solid overlay [13]. Their one-step growth was now compared, to that of their parent virus, the Lister strain of vaccinia virus (Fig. 1). As expected, the LP variant, reached the highest infectious titer within 23 hours. Although the Lister parent virus reached a similar titer, additional 12 hours were required in order to achieve it. On the other hand, the growth of the other two variants: MP and SP, was significantly delayed and the highest titer reached was also lower, especially as compared with MP (Fig. 1).

The animal model we used in order to evaluate the pathogenicity of the different variants of the Lister strain of 

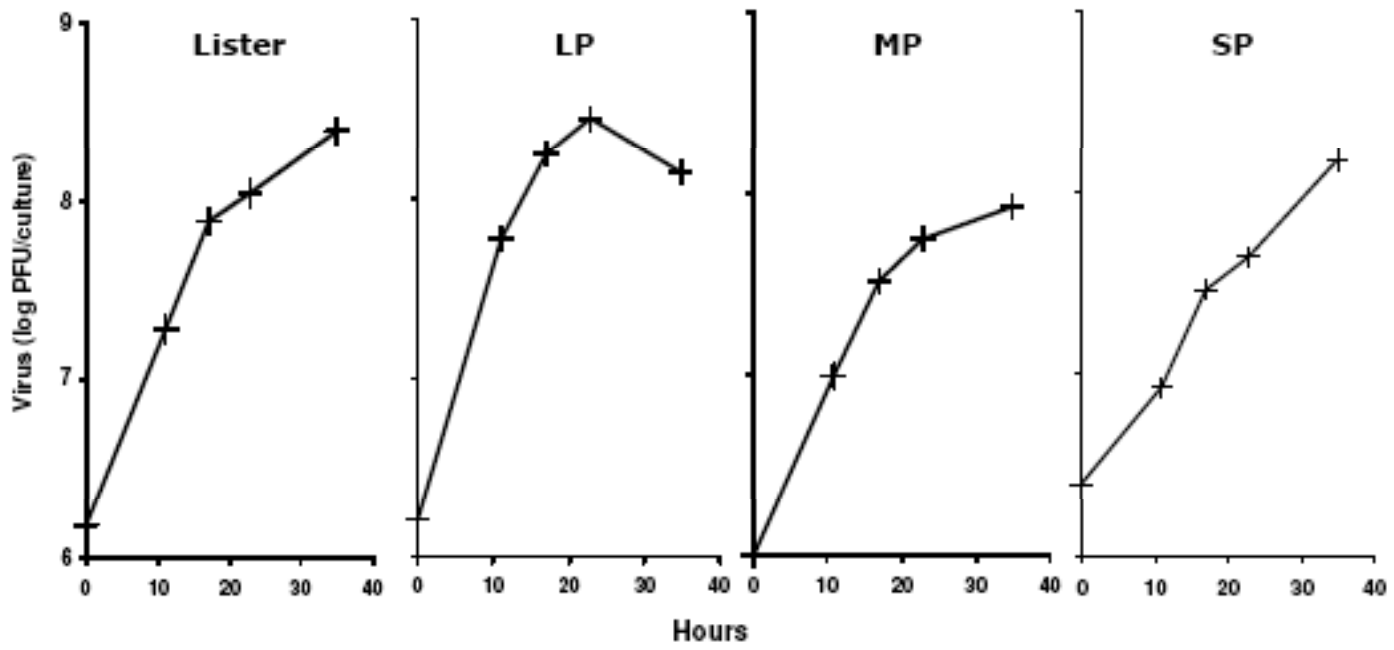

Fig. (1). Virus Growth. BS-C-1 cells were infected with the Lister stock and with the variants LP, MP and SP, at a multiplicity of infection of 3 PFU per cell. After $1 \mathrm{~h}$, the cells were washed twice in order to remove unadsorbed virus and medium containing $2 \%$ NBCS was added. The infected cultures were further incubated at $37^{\circ} \mathrm{C}$. At the indicated times, cultures were harvested and the titers of virus were determined by plaque assay.

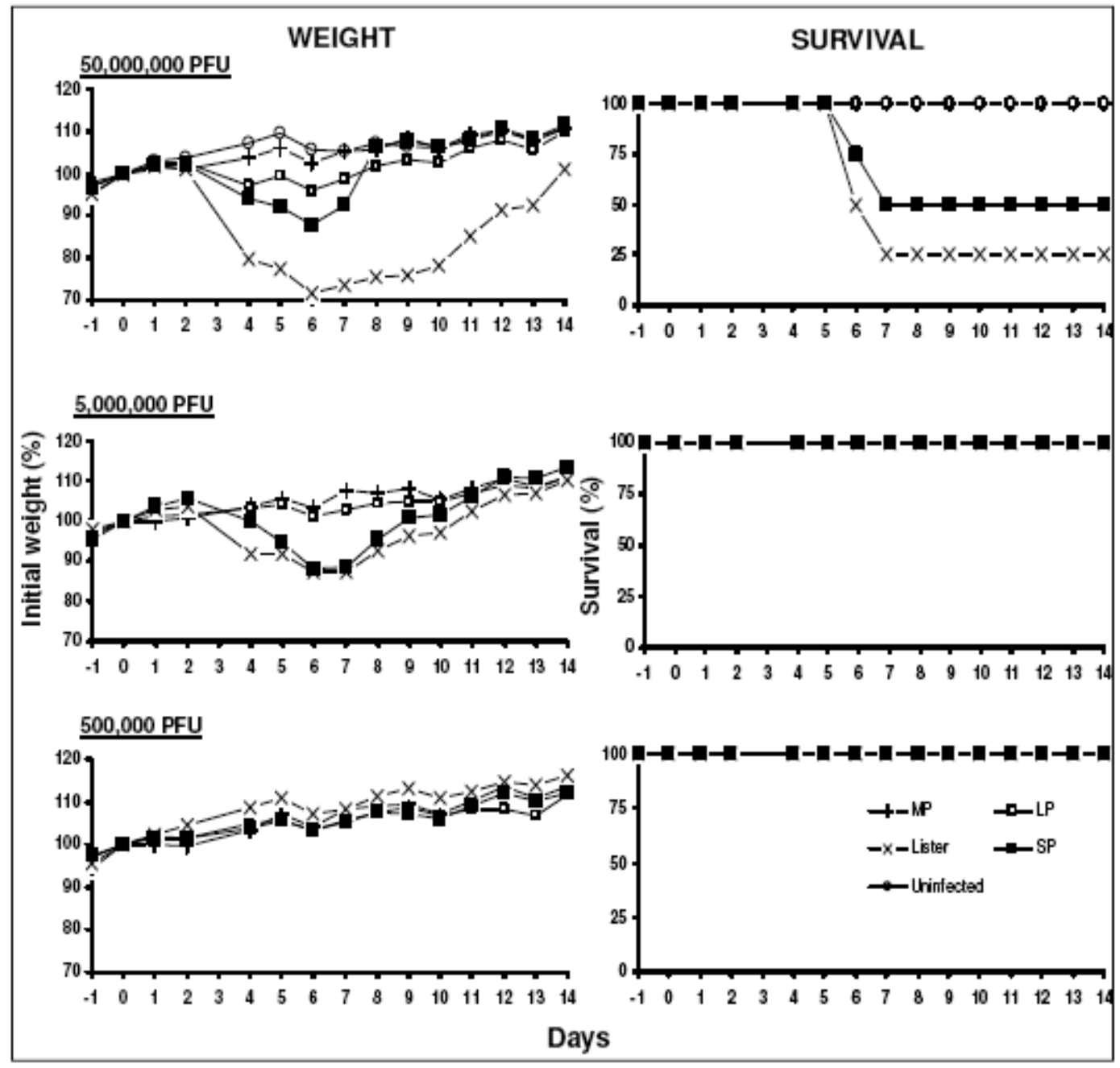

Fig. (2). Virulence for mice. Groups ( $n=4)$, of 4-5 weeks old mice, were intranasally inoculated with different doses of the Lister, LP, MP and SP variants, at a volume of $20 \mu \mathrm{l}$. The weight of the mice was determined daily and those that lost more than $25 \%$ of their initial weight were euthanized. The percentage of the weight of the mice at days before and after infection, relative to their initial weight, is plotted. The weight of uninfected mice was also followed. The survival of the infected mice is presented as well. Standard deviation was in general less than $2 \%$. 


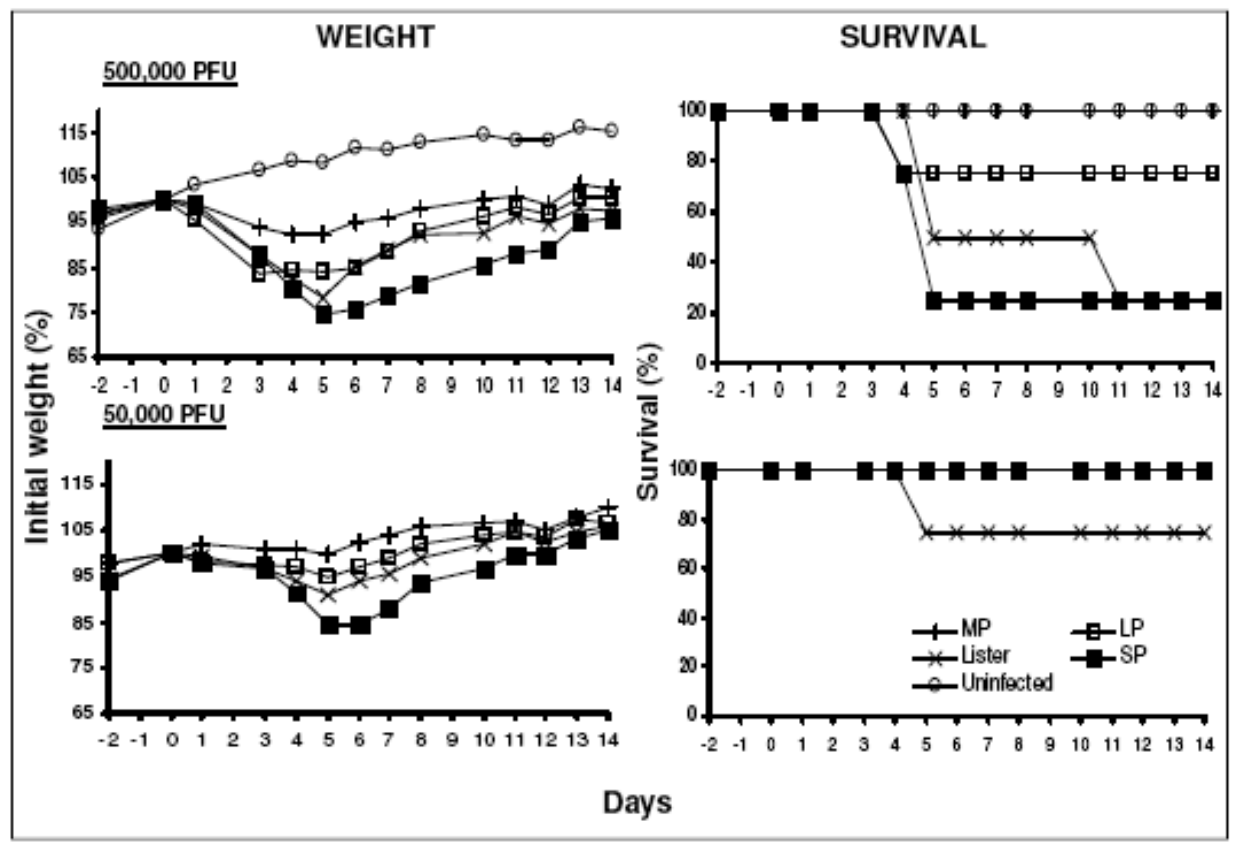

Fig. (3). Virulence for mice. The mice were injected intracranially, at a volume of $30 \mu \mathrm{L}$. The follow-up was as described in the legend of Fig. (2).

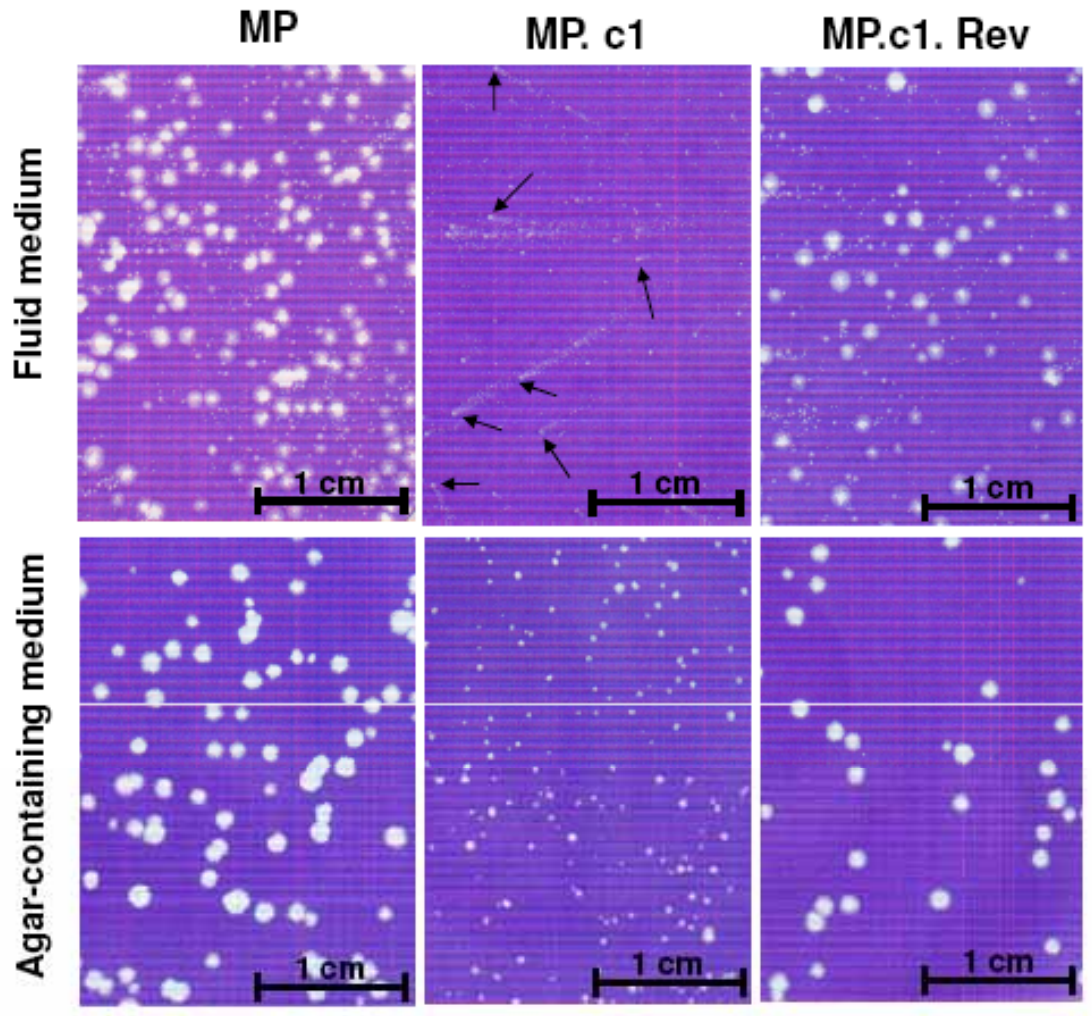

Fig. (4). Plaque morphology of the MP variant, the recombinant MP.c1 and its revertant MP.c1.Rev. Following adsorption, fluid medium or agarcontaining overlay, was added. After 2 days of incubation at $37^{\circ} \mathrm{C}$ the cultures were fixed and stained with $0.1 \%$ crystal-violet in $20 \%$ ethanol.

vaccinia virus was previously applied by Turner [15]. When mice were infected intranasally with 50,000,000 PFU, the Lister strain was found to be the most virulent, while the SP variant was slightly less pathogenic, as determined by both the loss of weight of the infected mice and their survival (Fig. 2). The lungs of the mice infected with these two viruses, loosing more than $25 \%$ of their initial weight, contained high titers of virus $\left(1.4-3.3 \times 10^{7}\right.$ PFU per gram of tissue). The difference between the Lister strain and the SP variant was less pronounced, as the loss of weight and the survival are concerned, when the mice were infected with 5,000,000 PFU (Fig. 2). In contrast to these two viruses, both 
LP and MP were significantly less virulent to the mice, as judged by the loss of weight, and all mice infected with these two viruses, even with the highest virus dose, did survive (Fig. 2). When antibodies against vaccinia virus in the sera of the survived mice of this experiment, collected 14 days after infection, were determined by ELISA, it was found that all mice posses such antibodies (data not presented).

Intracranial inoculation of mice with 500,000 PFU of virus showed that while SP variant, Lister strain and LP variant were virulent for mice and significantly caused their loss of weight (especially noticed on the fifth day following injection), the MP variant was the most attenuated and all mice infected with this variant survived (Fig. 3). The high virulence of the Lister and the SP variant, as compared to LP and MP variants, was also demonstrated when mice were infected with 50,000 PFU (Fig. 3). All mice infected with 5,000 PFU of each of the four viruses, did survive (not shown).
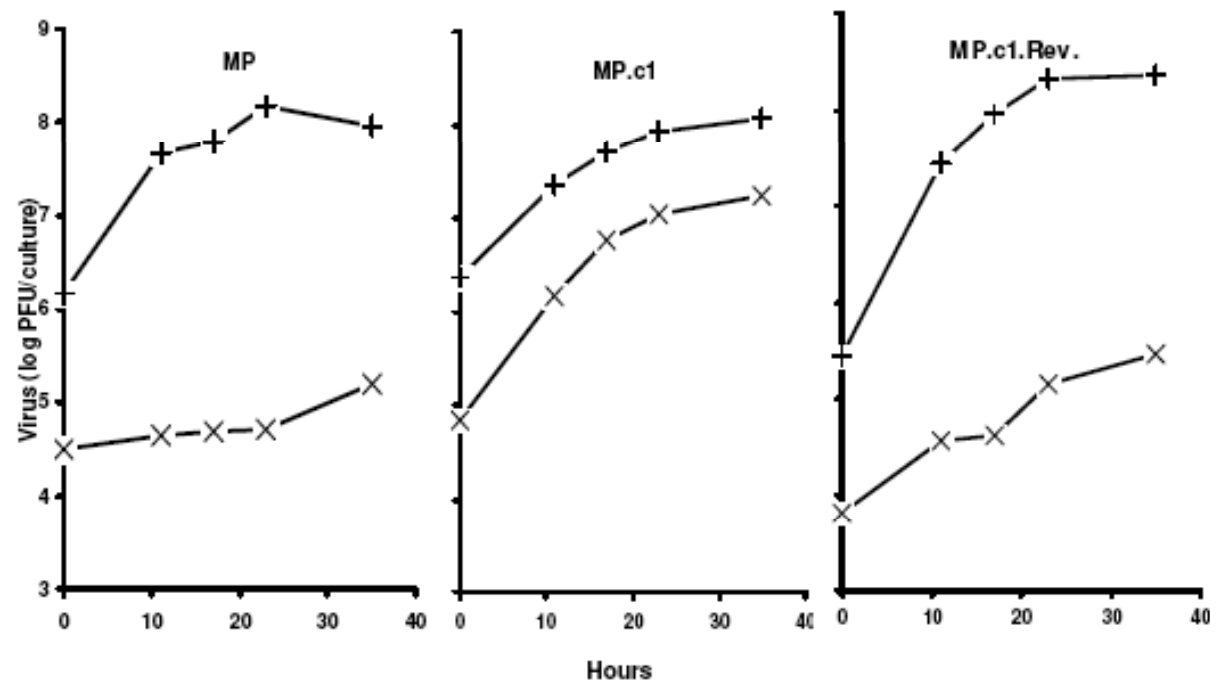

Fig. (5). Virus growth. The growth of MP, MP.c1 and MP.c1-Rev in BS-C-1 was followed, as described in the legend of Fig. (1). Except that the titer of the virus was determined separately in the infected cells ( $\mathrm{x}$-cell-associated virus) from that in the medium ( + -released virus).

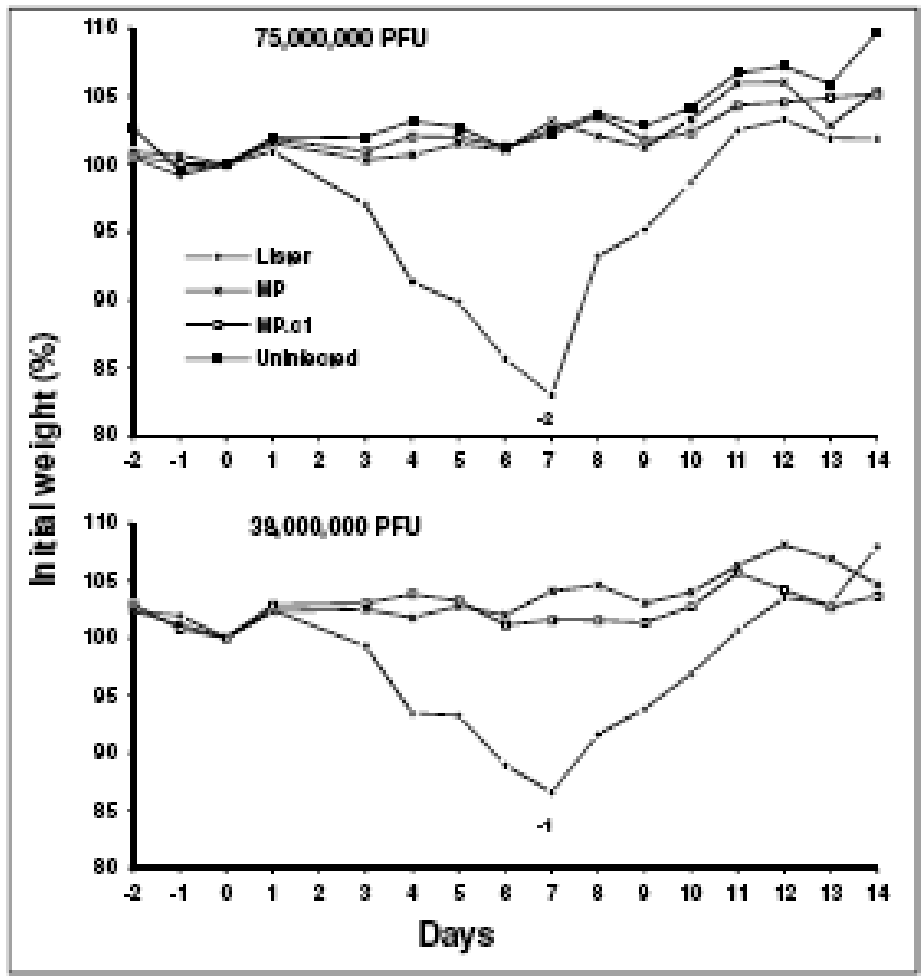

Fig. (6). Virulence for mice of the Lister strain, MP variant and the recombinant MP.c1. following intranasal inoculation. The weight of the mice was determined daily and those that lost more than $25 \%$ of their initial weight were euthanized. The percentage of the weight of the mice at days before and after infection, relative to their initial weight, is plotted. The weight of uninfected mice was followed as well. The numbers of euthanized mice are indicated $(-1$ or -2$)$. Standard deviation was in general less than $2 \%$. 
All four viruses: the Lister mixed stock, as well as, the LP, MP and SP variants, infecting mice intranasally with 10,000 PFU, protected them against a challenge of 50,000 PFU of the highly pathogenic Western Reserve (WR) strain of vaccinia virus, infecting the mice 14 days afterwards (data not presented).

\section{Construction of a Recombinant of the MP Variant, having C-terminal Truncated A33R Protein}

The results obtained so far, suggest that the MP variant of the Lister strain of vaccinia virus is the most attenuated virus, as compared with the mixed population of the parent Lister strain and the LP and SM variants isolated from it, while still being able to protect mice against a challenge with a lethal dose of the WR strain of vaccinia virus. Therefore, the variant MP was chosen by us for the construction of the new recombinant, having the truncated C-terminal A33R protein. The C-terminal truncated A33R gene, that we enriched by PCR, was derived from the DNA of the WR.c1 recombinant of vaccinia virus, previously constructed and isolated by us [14]. Following homologous recombination of the MP variant with the DNA of the A33R-truncated gene, a virus forming small plaques under agar-containing medium, was isolated and purified by serial plaque-to-plaque transfers. This virus, (MP.c1), formed comet-shaped plaques in cell cultures supplemented with fluid medium, as indicated by arrows in Fig. (4); such morphology is typical for viruses releasing high numbers of progeny virus from the infected cells [16]. The truncation of 35 amino acids in the C-terminal end of the A33R protein of MP.c1 was confirmed by sequence base analysis of the gene encoding this protein, which was found to be identical to that of the WR.c1 recombinant [14]. Furthermore, in order to ensure that the recombinant MP.c1 differs from its parent MP virus by the truncated A33R gene only, homologous recombination of MP.c1, with the DNA encoding the normal A33R gene, obtained from the WR strain, was performed. This reversed recombination gave rise to the revertant virus (MP.c1.Rev),

\section{WEIGHT}
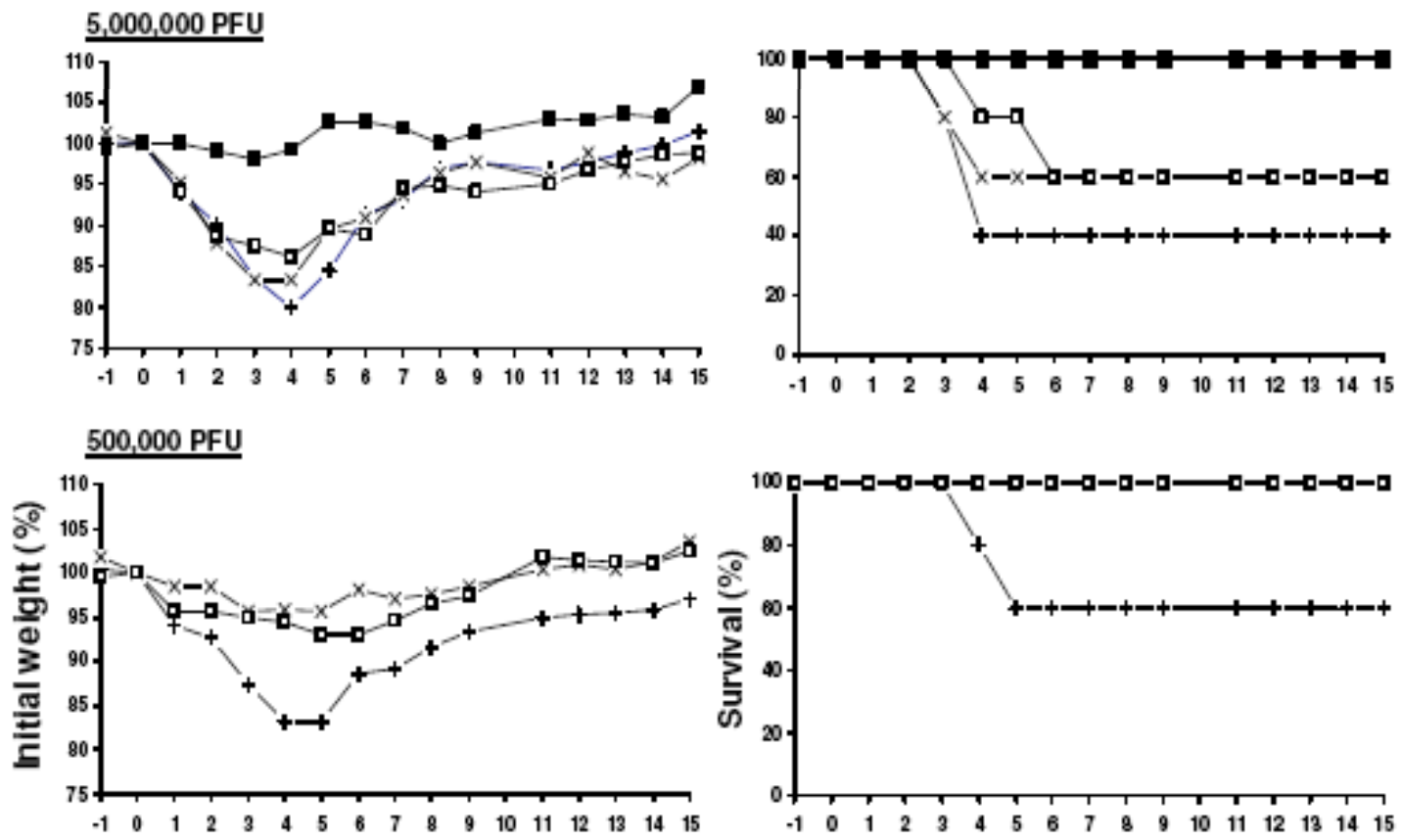

50,000 PFU
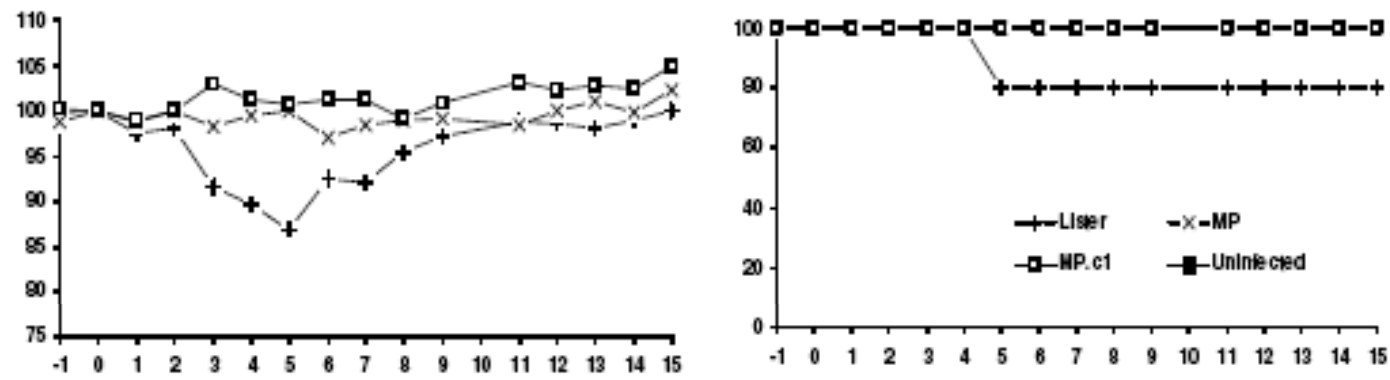

Days

Fig. (7). Virulence for mice of the Lister strain, MP variant and the recombinant MP.c1, after intracranial inoculation. Groups of mice (n=5) were injected with different doses of virus. The weight of the mice was determined daily and the percentage of the weight of the mice at days before and after infection, relative to their initial weight, is plotted. Those mice that lost more than $25 \%$ of their initial weight were euthanized and the survival of the infected mice is also presented. Standard deviation was in general less than $2 \%$. 


\section{WEIGHT}

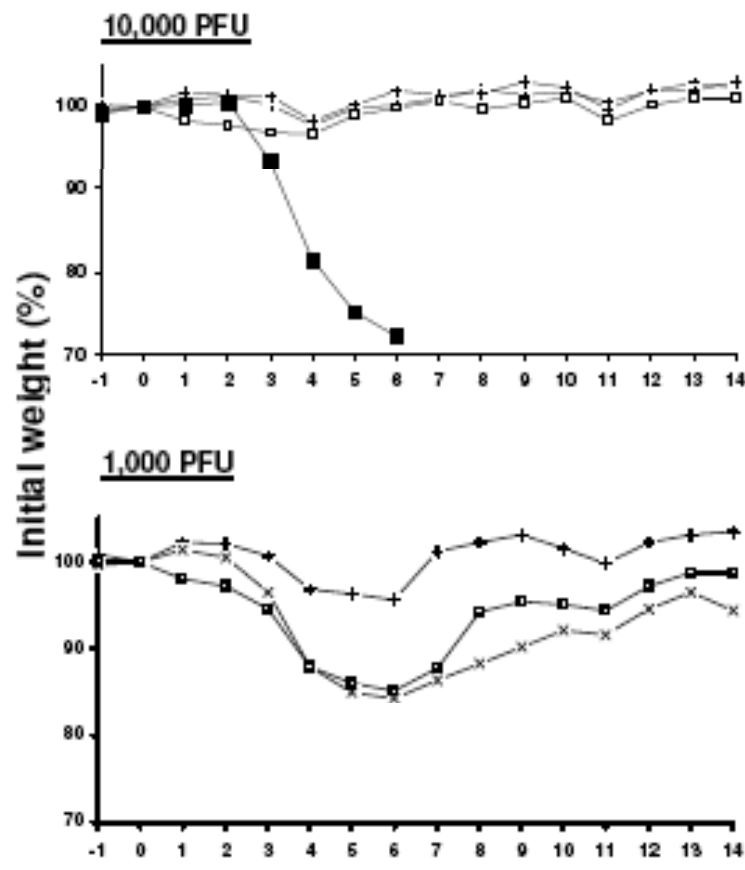

SURVIVAL

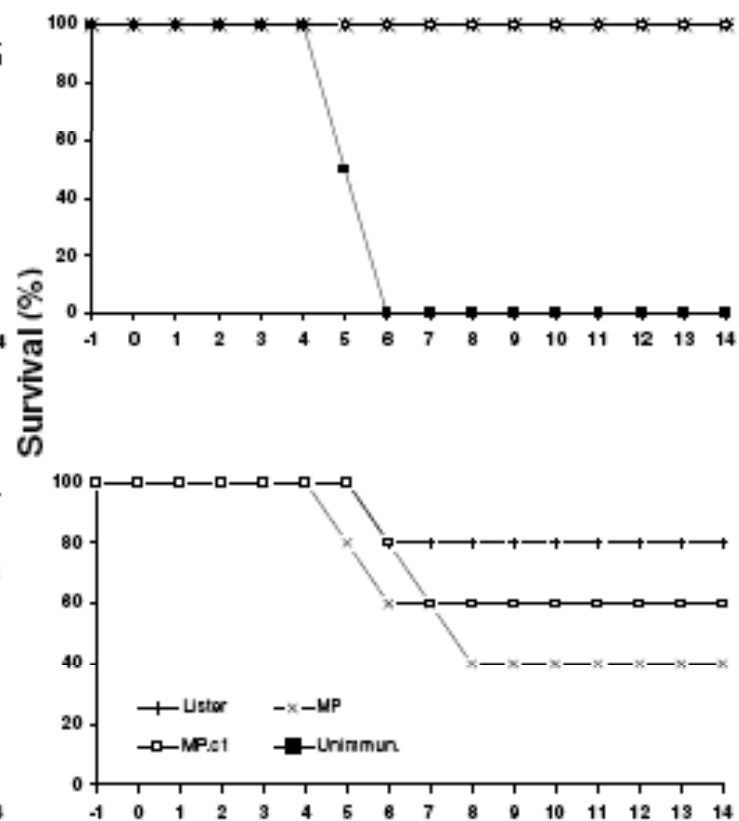

Days

Fig. (8). Protection of mice infected with the Lister strain, the variant and the recombinant MP.c1. Mice (n=5) were intranasally infected with 10,000 or 1,000 PFU per mouse. After 14 days, the mice were infected intranasally with 50,000 PFU of the pathogenic WR strain. The weight of the mice was followed for 14 days thereafter. Survival of the mice is also presented. One group of mice was not immunized (Unimmun.) and served as a control. Standard deviation was in general less than $2 \%$.

which we then isolated and purified and, as expected, had normal A33R sequences (data not presented) and exhibited similar plaque morphology to that of the MP variant under fluid medium, as well as, under agar-containing medium (Fig. 4).

The one-step growth curves of the MP variant, the recombinant MP.c1 and the revertant MP.c1.Rev, are presented in Fig. (5). While the MP variant and MP.c1.Rev release only $0.1 \%$ of their progeny virus made in the infected cells into the culture media at the end of their growth cycle, MP.c1 releases 100 folds more free viruses (Fig. 5). This resulted in the comet shape plaques formed by this virus under fluid medium, as indicated by arrows in Fig. (4).

The pathogenicity of the recombinant MP.c1 for mice was then followed. An inoculum of 75,000,000 PFU of MP.c1 introduced intranasally, did not affect the weight of the mice, similarly to its MP parent virus, in contrast to the Lister strain that caused the mice to significantly loose weight and two of the four mice of the group, to reach their critical low weight on the $7^{\text {th }}$ day following infection (Fig. 6). Furthermore, infection of mice with a lower dose of the Lister strain $(38,000 \mathrm{PFU})$ still caused one mouse to loose its weight reaching its critical value, while there was not a single mouse infected with the MP variant or with the MP.c1 recombinant that was affected (Fig. 6).

Intracranial inoculation, with three different doses of virus, revealed once again that the Lister strain is the most pathogenic strain, when infecting the mice at the three different doses of virus (Fig. 7). The recombinant MP.c1 was found to be somewhat less virulent than its parent virus (MP variant), when the survival of the mice was determined following infection with 5,000,000 PFU (Fig. 7).

The capability of the viruses to protect mice against a challenge with a lethal dose of the pathogenic WR strain of vaccinia virus, infecting the mice 14 days later, was then followed. It was found that while 10,000 PFU of the three viruses induced full protection, 1,000 PFU of the Lister virus protected $80 \%$ of the mice and MP variant was somewhat less effective in this regard than the recombinant MP.c1 (Fig. 8).

\section{CONFLICT OF INTEREST}

None declared.

\section{ACKNOWLEDGEMENTS}

None declared.

\section{REFERENCES}

[1] Henderson DA. Smallpox: clinical and epidemiologic features. Emerg Infct Dis 1999; 5: 537-9.

[2] Fenner F, Henderson DA, Arita I, Jezek Z, Ladnyi ID. Smallpox and its eradication. Geneva: World Health Organization; 1988.

[3] Henderson DA, Moss B. Smallpox and vaccinia. In: Plotkin SA, Orenstein WA (Eds.), Vaccines. Philadelphia, PA: WB Sauders; 1999; 74-97.

[4] Henderson DA, Inglesby TV, Bartlett JG, et al. Smallpox as a biological weapon: medical and public health management. Working group on civilian biodefence. J A M A 1999; 281: 2127-37.

[5] Henderson DA. The looming threat of bioterrorism. Science 1999 283: $1279-82$. 
[6] Goldstein JA, Neff JM, Lane JM, Koplan JP. Smallpox vaccination reaction, prophylaxis and therapy of complication. Pediatrics 1975; 55: 342

[7] Sinclair MC, Lane JM, Donald WJ, Esco LC. Complications of smallpox vaccination in Alabama 1968. Southern Med J 1972; 65: 41-4.

[8] Gurvich EB. The age dependent risk of postvaccination complication in vaccines with smallpox vaccine. Vaccine 1992; 10: 96-7.

[9] Hochstein MV, Huber HC, Stickl H. Virulenz und immunogentat eines midifizierten vaccinia-virus (Stamm MVA). Z Immun Forsch 1972; 144: 140-5.

[10] Mayr A, Stickl H, Muller HK, Danner K, Singer H, Der pockenimpfstamm MVA: Marker, genetischestruktur, erfahrungen mit der parenteralen schtzimpfung und verhalten im abwehrgeschwachten organismus. Zbl Bakt Hyg 1978; 167: 375-90.

[11] Sutter G, Moss B. Novel vaccinia vector derived from the host range restricted and highly attenuated MVA strain of vaccinia virus. Dev Biol Stand 1995; 84: 195-200.
[12] Stitelaar KJ, Kuiken T, de Swart RL, et al. Safety of modified vaccinia Ankara (MVA) in immune suppressed macaques. Vaccine 2001; 19: 3700-9.

[13] Abdalrhman I, Gurt I, Katz E. Protection induced in mice against a lethal orthopox virus by the Lister strain of vaccinia virus and modified vaccinia virus Ankara (MVA). Vaccine 2006; 24: 4152-60.

[14] Katz E, Ward BM, Weisberg AS, Moss B. Mutations in the vaccinia virus $A 33 R$ and $B 5 R$ envelope proteins that enhance release of extracellular virions and eliminate formation of actincontaining microvilli without preventing tyrosine phosphorylation of the A36R protein. J Virol 2003; 77: 12266-75.

[15] Turner GS. Respiratory infection of mice with vaccinia virus. J Gen Virol 1967; 1: 399-402.

[16] Payne LG. Significance of extracellular virus in the in vitro and in vivo dissemination of vaccinia virus. J Gen Virol 1980; 50: 89-100.

(C) Gurt and Katz; Licensee Bentham Open.

This is an open access article licensed under the terms of the Creative Commons Attribution Non-Commercial License (http://creativecommons.org/licenses/ by-nc/3.0/) which permits unrestricted, non-commercial use, distribution and reproduction in any medium, provided the work is properly cited. 